\title{
ESPECIALIZACIÓN DEL DISCURSO: UNA CARACTERIZACIÓN DESDE EL SISTEMA DE LA OBLIGACIÓN ${ }^{*}$

\author{
DISCOURSE SPECIALIZATION: A CHARACTERIZATION FROM \\ THE OBLIGATION SYSTEM
}

\author{
ROSA MARÍA GUTIÉRREZ \\ Universidad Católica de Temuco. Temuco, Chile. \\ rmgutierrez@utc.cl
}

\section{RESUMEN}

Este estudio de alcance descriptivo, enmarcado en la Gramática Sistémico-Funcional (GSF) (Matthiessen, 2006, 2007; Caffarel, Martin \& Matthiessen, 2004), tiene por objetivo caracterizar el discurso especializado oral y escrito, a partir de la variación probabilística que presentan las configuraciones lexicogramaticales realizadoras de la obligación en español. Para alcanzar este objetivo se toma como contexto de observación un corpus multirregistro caracterizado por el cruce de las variables de oralidad / escritura y grado de especialización, esto es, desde el constructo de registro (Halliday, 1982a) modo y campo, respectivamente. La explotación automática se desarrollará utilizando la interfaz de consulta y etiquetaje lingüístico El Grial (Parodi, 2007), la que nos permite acceder a la frecuencia absoluta de instanciación de cada término de la red sistémica de obligación. Sobre dicha frecuencia se estima la probabilidad condicionada de ocurrencia y, sobre esta última, la variación del sistema de la obligación en el contexto del corpus, utilizando para este último cálculo un error global del 5\%. Los resultados evidencian que existe una correlación directamente proporcional entre el grado de especialización y el grado de obligación implicado en los diferentes registros del corpus.

Palabras claves: LSF, GSF, modulación, obligación, especialización, oralidad, escritura, trabajo de corpus, probabilidades condicionadas.

\section{ABSTRACT}

From a Systemic Functional Grammar (SFG) approach, the present descriptive study (Matthiessen, 2006, 2007; Caffarel, Martin \& Matthiessen, 2004) is aimed at characterize

* Proyecto Fondecyt 1060440. 
the specialized oral and written discourse, from the probabilistic variation that present of the realizations of the obligation system in Spanish, which tend to become critical features when characterizing oral and rather specialized written language. To achieve our objective, we take as context of observation a multiregister corpus, characterized by the crossing of the oral/writing and degree of specialization variables, that is, from the register construct perspective (Halliday, 1982a), mode and field respectively. The automatic exploitation will be carried out through the linguistic tagger and query interface, El Grial (Parodi, 2007), which allows us to access the absolute frequency of instantiation of each term in the systemic network of obligation. Upon this frequency, we estimate the conditioned probability of occurrence and, upon the latter, the obligation system variation in the corpus context. For this last calculus, we assume an error estimation of 5\%. Results show that there is a direct proportional correlation between the degree of specialization and the degree of obligation present in the different registers of the corpus.

Keywords: SFL, SFG, modulación, obligation, specialization, oral, writing, corpus based, conditioned probability.

Recibido: 23-10-2008. Aceptado: 13-10-2009.

\section{INTRODUCCIÓN}

Enmarcado en la Gramática Sistémico-Funcional (GSF), el presente estudio adhiere al propósito mayor de contribuir a la caracterización del discurso especializado. Con el mismo propósito se ha estudiado el comportamiento de diversos mecanismos lexicogramaticales, entre los cuales destaca el estudio de las nominalizaciones (metáfora gramatical), especialmente de las deverbales, pero también de las deadjetivales (Cademártori, Parodi \& Venegas, 2007; Marinkovich, 2007); el estudio de los tipos de verbos o procesos (Sabaj, 2007a), el de los papeles temáticos involucrados en esos procesos (Sabaj, 2007b), el de los modos de organización discursiva asociada a la mayor o menor especialización y, más recientemente, los estudios sobre la conformación retórica de géneros académicos y profesionales (Gutiérrez, 2009a,b; Ibáñez, 2009; Parodi, 2009).

No debe extrañar la diversidad de los puntos de observación pues, tal como lo ponen de manifiesto Gotti (2003) y Parodi, Venegas, Ibáñez y Gutiérrez (2009), la especialización, tal como el lenguaje mismo, es un fenómeno multidimensional y, en consonancia con ello, debe ser abordado a partir de múltiples ángulos. En este último sentido, este estudio se suma a la diversidad de puntos de vistas, por cuanto no sólo proporciona una mirada desde un nuevo conjunto de rasgos, sino

que además lo hace desde un marco de análisis no utilizado antes para el español, tal es, como ya se dijo, la GSF. Esta es una gramática descriptiva orientada al sistema, es decir a las relaciones paradigmáticas más que al sintagma y se encuentra enmarcada en una teoría del sistema del lenguaje verbal, la Lingüística Sistémico- 
Funcional (LSF). A partir de tal sustento, la gramática se organiza sobre la base de la hipótesis metafuncional (Halliday, 1982a; Halliday \& Matthiessen, 2004), desde la cual se ofrecen al menos tres puntos de observación para el análisis del discurso, a saber, el ideacional, el interpersonal y el textual. Estos, aunque diferentes, tienen la ventaja de formar parte de una misma comprensión de los fenómenos lingüísticos.

Si volvemos a observar los estudios antes mencionados (i.e. Cademártori et al., 2007; Marinkovich, 2007; Sabaj, 2007a, 2007b), pero ahora desde el cuadro de la hipótesis metafuncional (Halliday, 1984; Matthiessen, 2007), notaremos que ellos mayoritariamente dan cuenta de la construcción de significados ideacionales y textuales (Halliday, 1985a, Halliday, 1985b), es decir, de cómo se presenta la mayor especialización en términos de representación del conocimiento y en términos de la organización textual. Sin embargo, como sabemos, toda representación verbalmente construida y textualizada es además negociada en el marco del intercambio comunicativo. La negociación se asocia a la construcción de significados interpersonales (Martin, Matthiessen \& Painter, 1997; Halliday, 1984; Halliday \& Matthiessen, 2004), tercer componente metafuncional a partir del cual se abre la comprensión del lenguaje como medio dialógico de interacción humana (Halliday, 1984; Butt, Fahey, Feez, Spinks \& Yallop, 2000; Gómez-Macker, 2005), en cuyo marco los significados son presentados desde un determinado ángulo argumentativo.

En atención a lo anterior, resulta relevante, para ampliar la mirada sobre el discurso especializado, observar a través de qué recursos lexicogramaticales se negocia el intercambio de conocimiento en el contexto de la especialización. Se trata, sin duda, de un espacio de escaso desarrollo en los estudios discursivos, debido, probablemente, a la falta de sistematización en torno a los recursos interpersonales los que, a nuestro juicio, sólo con la propuesta organizativa de la LSF, comienzan a ser un núcleo consistente de estudio que permite diferenciar entre los distintos matices o grados que se involucran en la codificación verbal de los significados interpersonales. Para iniciar la exploración en este ámbito, tomamos uno de los subsistemas asociados a la construcción de este tipo de significados: la obligación, el cual se perfila como uno de los significados modales menos trabajado en la caracterización de los textos respecto de los recursos que se utilizan para negociar el significado.

Desde este marco, el objetivo de este estudio es caracterizar el discurso especializado oral y escrito, a partir de la variación probabilística que presentan las configuraciones lexicogramaticales realizadoras de la obligación en español. Utilizamos para esto un acercamiento al corpus basado en el corpus (Tognini-Bonelli, 2001). Además, dado que el sistema de la obligación, como veremos más adelante, constituye una gradiente de comportamiento fractal, articulada sobre la base del principio de congruencia (Gutiérrez, 2007a, Gutiérrez, 2007b), paralelamente se consigue observar el comportamiento probabilístico de la metáfora interperso- 
nal en la caracterización de los registros. Este último asunto complementa las anteriores aproximaciones desarrolladas sobre la base de la metáfora ideacional o nominalización. El artículo se estructura en tres secciones. En la primera de ella se presenta el sistema de la obligación desde el estrato semántico y desde su realización a nivel lexicogramatical. La segunda parte expone el marco metodológico de esta investigación. En tercer lugar presentamos los resultados y su discusión, tomando el sistema de la obligación como principio organizador. Finalmente, se presentan las principales conclusiones.

\section{MARCO TEÓRICO}

\subsection{La modulación de obligación desde el estrato semántico}

Desde la GSF y a nivel semántico, la obligación es un sistema asociado, como ya se ha dicho, a la comprensión del lenguaje verbal como un medio que posibilita la interacción entre los participantes de un intercambio dialógico. Bajo este sistema, al que conocemos como metafunción interpersonal (Halliday, 1982a), se aglutinan los significados que, de una parte, se relacionan con la naturaleza de lo que se está intercambiando en un evento de habla y, de otra, con los roles que los hablantes desempeñan en el intercambio. Según su naturaleza, los intercambios pueden corresponder a intercambios de información o intercambios de bienes y servicios. Respecto de los roles de los hablantes, éstos se clasifican en dos niveles. El primero corresponde a los roles propios de un evento semiótico verbal, es decir, rol de hablante, oyente, escritor o lector. El segundo, corresponde a los roles que se generan en cualquier proceso -semiótico- de intercambio, esto es, rol de demandante u ofertante (Halliday, 1984, 1985a; Matthiessen, 1995; Halliday \& Matthiessen, 2004).

De la confluencia entre la naturaleza de lo intercambiado y los roles de habla, surgen las cuatro funciones básicas del habla: aseverar, preguntar, requerir y ofertar (Matthiessen, 1995). Las dos primeras están asociadas a los roles de ofertante y demandante de información. Las otras dos se relacionan con demandar y ofertar bienes y/o servicios. En otras palabras, tal como lo muestra la red sistémica de la Figura 1, dar información es aseverar, dar bienes y servicios es ofertar, demandar información es preguntar y demandar bienes y servicios es requerir.

Mientras aseverar y preguntar son funciones del habla correspondientes a la zona semántica de una proposición; requerir y ofertar están asociadas a la de una propuesta (ver Figura 1). Esto implica que el contenido de una aseveración y/o de una pregunta puede ser evaluado en términos de verdad o falsedad, en tanto que el de un requerimiento y/o el de una oferta es evaluado en términos de rechazo o aceptación (Halliday \& Matthiessen, 2004). 


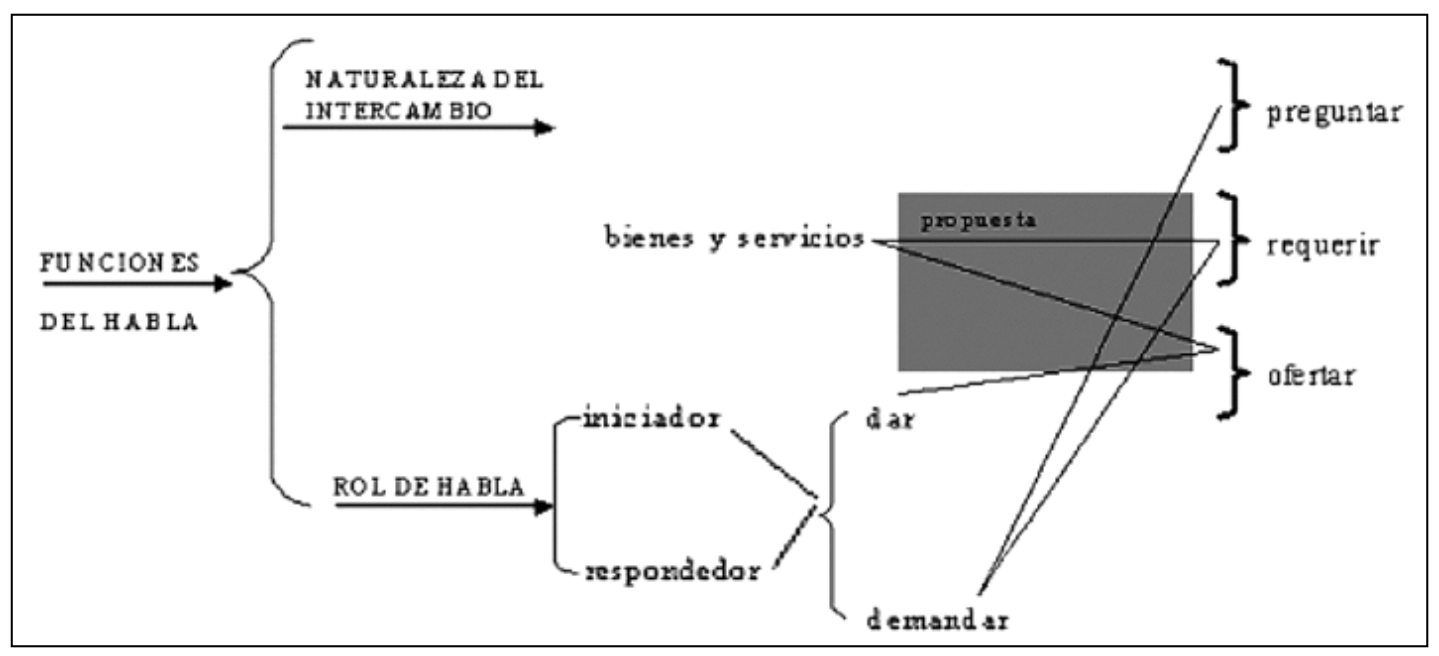

Figura 1. Red sistémico-semántica de las funciones del habla.

Cada una de las funciones básica del habla puede ser afirmada o negada, atenuada o enfatizada. La afirmación o negación se realiza a través del sistema de polaridad y la atenuación o enfatización, a través del sistema de modalidad. Este último es el que nos ocupa, pues, tal como se evidencia en la red sistémica de la Figura 2, la obligación se ubica como término en la condición de entrada que el sistema de la modalidad instaura.

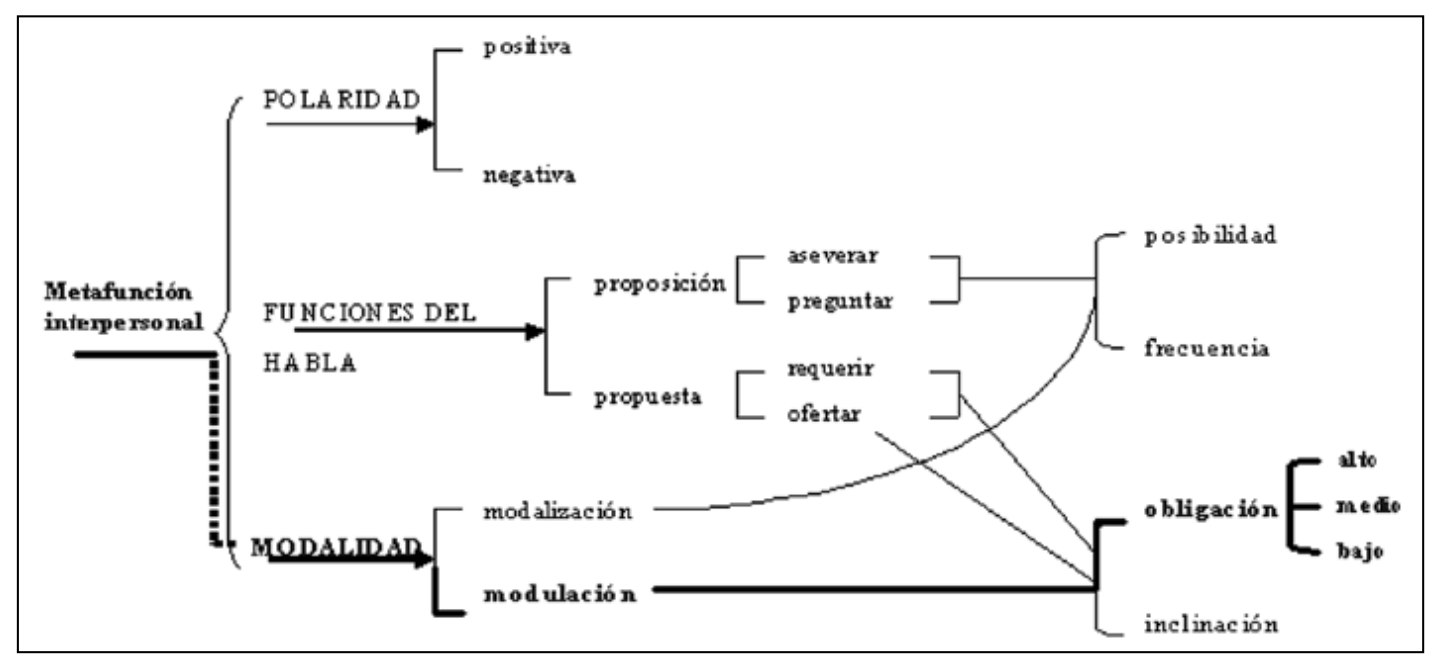

Figura 2. Ubicación del sistema de la obligación en la red sistémico-semántica de la interpersonalidad.

El sistema de modalidad, como podemos observar en la Figura 2, presenta dos términos u opciones que dan cuenta de la variación que la modalidad presenta según esté asociada a una proposición, en cuyo caso la llamamos modalización; o a una propuesta, en cuyo caso hablamos de modulación. La modalización, a nivel semántico, corresponde a la gradación de la certidumbre con que el hablante evalúa y presenta -para su interlocutor- la veracidad o falsedad de una proposición 
(Matthiessen, 1995; Martin et al., 1997). La modulación, por su parte, corresponde a la gradación del compromiso con que el hablante evalúa y presenta la aceptación o el rechazo de una propuesta (Martin et al., 1997; Halliday \& Matthiessen, 2004). Esta diferenciación que la GSF propone para los significados de la modalidad resulta clarificadora y posibilita, sobre la base de una terminología específica, una organización que no tiene antecedentes en otros estudios gramaticales ni lingüísticos, pues tradicionalmente suelen utilizarse los términos modalidad y modalización indistintamente para referirse al conjunto de significados asociados a la actitud del hablante.

En el marco de esta propuesta, el sistema de la obligación se presenta como un continuum que va desde lo más a lo menos obligativo o más modulado. Básicamente, se distinguen tres grados: alto, medio y bajo (Martin, 1992; Halliday \& Matthiessen, 2004). Más específicamente, diremos que la escala de la obligación se desplaza entre lo explícitamente apelativo y la apelación indirecta o modulada. Asignar un grado de obligación depende de dos aspectos del tenor que actúan simultáneamente. De una parte, depende de cuál es la relación que mantienen los participantes en el diálogo y, de otra, del compromiso que el hablante visualiza hay entre el requerimiento y quien es demandado.

\subsection{Realización lexicogramatical de la obligación}

Cada función del habla, a nivel lexicogramatical, se realiza en un modo clausular configurado en torno a un núcleo modal, esto es, a un sujeto y a un finito temporomodal específico y congruente. Así, la aseveración se realiza a través del modo declarativo de la cláusula; la pregunta, a través del modo interrogativo; el requerimiento, a través del modo imperativo; y la oferta, a través de lo que llamamos modo 'inclinativo'. En todos los casos, la congruencia del núcleo modal puede verse disminuida por el uso de configuraciones lexicogramaticales no congruentes o metafóricas, es decir, configuraciones que, a nivel sintagmático, realizan alguna función - de la estructura funcional de la cláusula- por medio de unidades de rango que no son las ontogenéticamente empleadas (Matthiessen, 1995).

En el sentido de lo recién expuesto y en tanto que escala de grados, la modulación de obligación constituye un sistema que agrupa las opciones para atenuar la demanda que congruentemente es realizada por un núcleo modal conformado por un sujeto de segunda persona y un finito temporomodal de presente del imperativo. En español, tal núcleo modal corresponde a lo que conocemos como modo imperativo de la cláusula.

Dado que la gradación se establece sobre la base del principio de congruencia, el sistema de la modulación no es otra cosa que una gradiente tendiente a la metaforización (gramatical interpersonal) de la obligación. Siguiendo la propuesta de Gutiérrez (2007a,b), identificamos seis configuraciones lexicogramaticales que realizan obligación en español, tales son: (a) el modo (verbal y clausular) impera- 
tivo, (b) las configuraciones modales, (c) los adjetivos introducidos en el contexto de una cláusula relacional, (d) los adverbios, (e) las configuraciones con un verbo cuya naturaleza léxica es obligativa y (f) el modo interrogativo de la cláusula, tal como se muestra, a continuación, en la Figura 3.

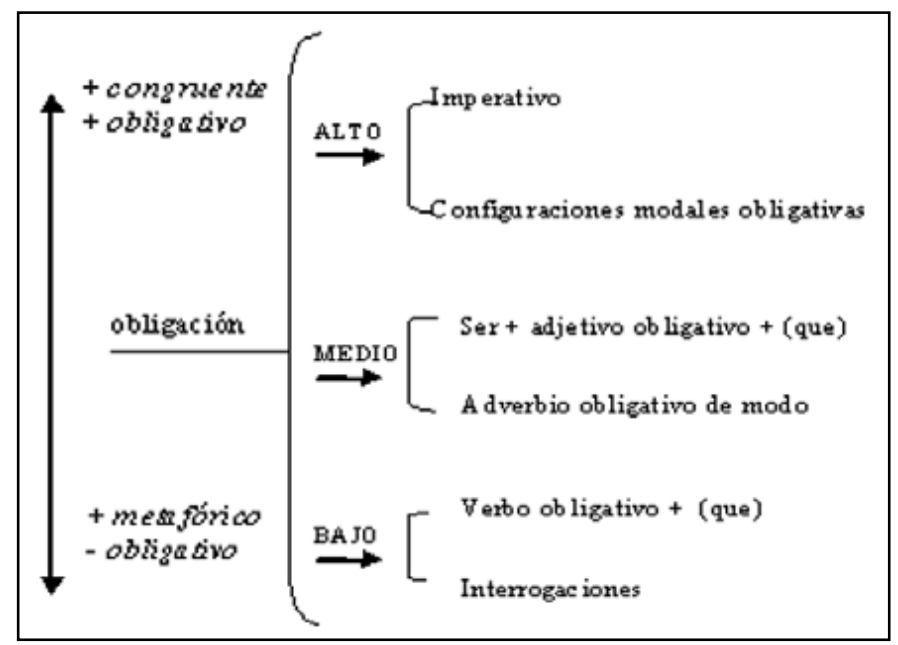

Figura 3. Gradiente de la obligación para el español.

Como ya se explicitó y tal como notamos en la Figura 3, las configuraciones están dispuestas en torno a tres movimientos que modulan el requerimiento implicado en una demanda. Así, el grado más alto agrupa configuraciones de mayor congruencia, en tanto que las de grado bajo corresponden a realizaciones metafóricas (i.e. metáforas interpersonales) en su propio derecho. La gradación tiene un comportamiento fractal, lo que quiere decir que se replica al interior de cada una de los términos del sistema, tal como se presenta en la Figura 4.

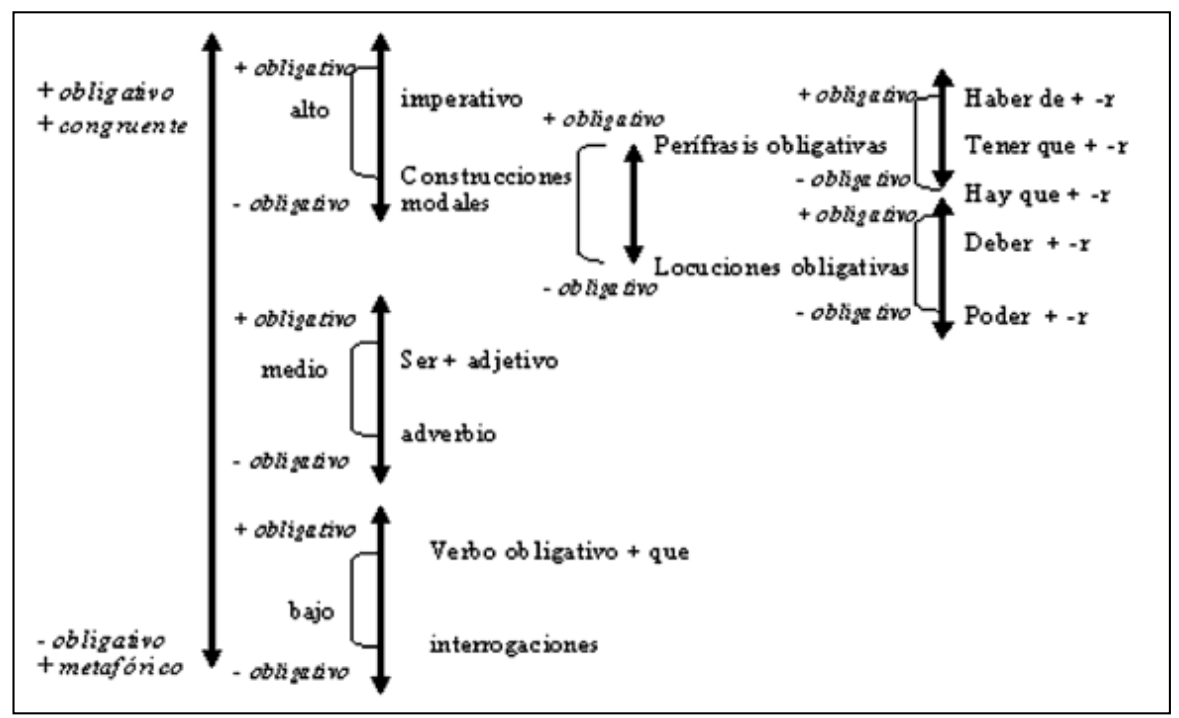

Figura 4. Comportamiento fractal de la gradación. 
El fenómeno de la fractalidad se debe, de una parte, a la variabilidad léxica de algunas de las configuraciones y, de otra, a la interacción con los sistemas de tiempo y persona. Respecto de los tiempos, el sistema de la obligación presenta una gradación en el marco de la tríada presente - futuro - condicional. Dentro de ella, el presente corresponde al tiempo propio (i.e. prototípico y congruente) de la modulación, por cuanto es el que conlleva la concreción e inmediatez que caracteriza a las demandas involucradas en las propuestas (Palmer, 2001; Klinge $\&$ Hoeg, 2005). El futuro, tiempo que proviene de la perífrasis obligativa del latín 'amar he'< amaré, conserva el valor obligativo en conjugación con algunas de la personas interactuantes, especialmente en su carácter de promesa (grado de inclinación máxima) y en su uso condicional (Gili Gaya, 1979; Bosque, 1990). Por último, el pasado es un tiempo que no realiza factualidad (Rojo \& Veiga, 1999) y, en consecuencia, no puede ser asociado a una propuesta. Vista desde el sistema de la obligación, la tríada temporal se presenta como sigue (ver Figura 5).

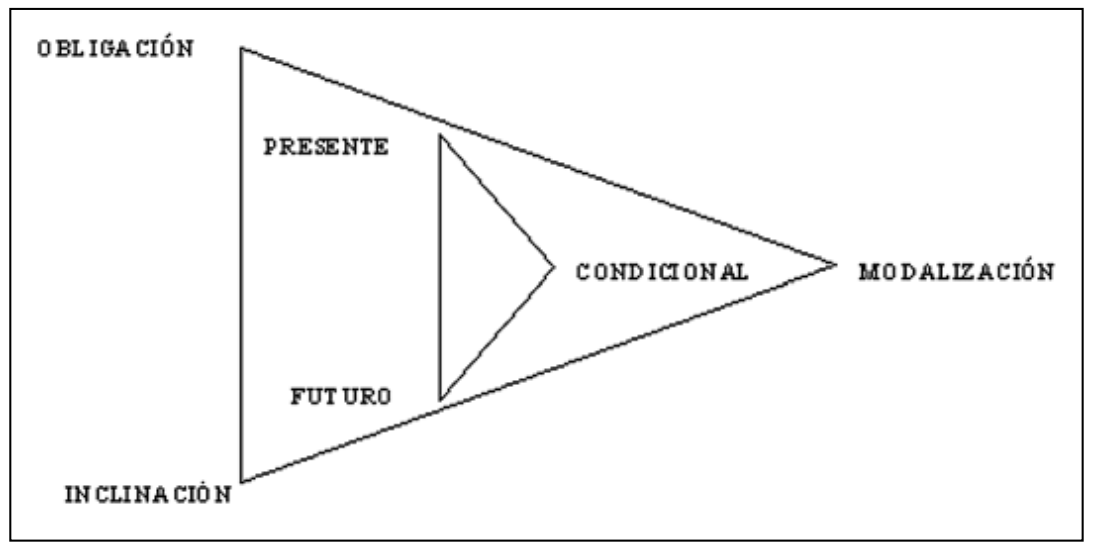

Figura 5. Disposición del sistema de tiempo en relación a la modulación y la modalización.

En relación a la gradiente de persona, la segunda persona resulta ser, según las definiciones teóricas (RAE, 1973; Hernández, 1995; Di Tullio, 1997; Escandell, 1999; Garrido, 1999), la persona directamente apelada en una demanda de bienes y servicios y, en este sentido, constituye el eje congruente en torno al cual se gradúa la obligación desde el sistema de persona.

La modulación de obligación cuyo sujeto corresponde a primeras personas, aún manteniendo su carácter obligativo, en conjugación con los tiempos definidos para este sistema, se acerca a las propuestas inclinativas, por cuanto, la primera persona singular es el eje central (y el sujeto congruente) del sistema de la inclinación. La primera plural, en cambio, comienza a distanciarse de la realización congruente, pues al involucrar tanto al 'yo' como al 'tú' (primera inclusiva), pone de manifiesto la intención inclinativa del 'yo', a la vez que atenúa la demanda hacia 
el 'tú', realizando por tanto una zona semántica difusa entre obligación e inclinación. La tercera persona, por su parte (también llamada no-persona por Benveniste (1969)) es una cuya presencia en las construcciones lexicogramaticales hace que éstas se acerquen más a la zona semántica de las proposiciones y, por tanto, de las declaraciones. La Figura 6 presenta el continuum de grado que proponemos para el sujeto.

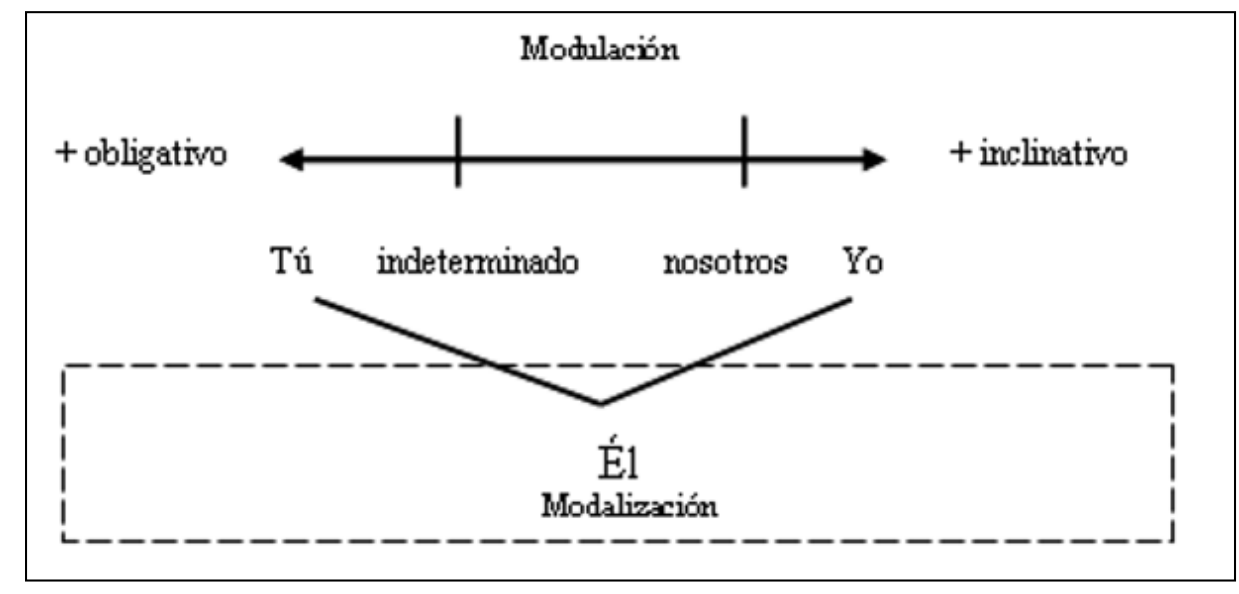

Figura 6. Relación del sistema de persona con el de modalidad.

Como notamos a partir de lo recién expuesto, la interacción de la obligación con los sistemas de tiempo y persona genera amplias zonas de difusión, ambigüedad y traslapo, todos éstos, factores que resultan de difícil manejo cuando se pretende estudiar la modalidad. Pese a ello, creemos que la distinción es considerablemente productiva, dado que permite, en primer lugar, poner en relación el sistema de la obligación con el de la inclinación, su par adyacente, y con el de la modalización (Gutiérrez, 2007a). En segundo lugar, porque, al menos en los polos de las relaciones se presenta una fina distinción, con un alto grado de detalle (delicacy) que tradicionalmente los estudios respecto de la modalidad no suelen desarrollar. Así, por ejemplo, en las gramáticas del español (RAE, 1973; Gili Gaya, 1979; Seco, 1980; Hernández, 1986; Gómez, 1988; Di Tullio, 1997; Porto, 1991; Alarcos, 1999; Bosque \& Demonte, 1999) y en los estudios sobre modalidad (Palmer, 2001; y Klinge \& Hoeg, 2005) se reconoce que 'tener + que' es una perífrasis que, en español, realiza obligación. Sin embargo, el detalle pone de manifiesto que la perífrasis sólo será obligativa cuando el verbo 'tener' aparezca asociado a un finito temporomodal de presente o futuro del indicativo y a un sujeto de segunda persona, de primera inclusiva o indeterminado.

Teniendo en cuenta la gradación de obligación que se produce en torno al sistema de tiempo y persona, a continuación revisamos con un poco más de detalle la realización de cada uno de los grados de obligación. 
a) Grado alto de obligación: imperativo y configuraciones modales obligativas.

En el contexto proporcionado por el grado alto, el 'imperativo' es la realización más congruente y, en este sentido, la que realiza con mayor fuerza o menor modulación la obligación implicada en una demanda. El imperativo como modo clausular y como modo del paradigma verbal tiene su uso restringido al núcleo modal congruente, es decir, a un sujeto de segunda persona y a un finito temporal de presente.

Las 'configuraciones modales obligativas' comienzan a distanciarse de la congruencia realizada por el imperativo. Esto pues, aun cuando desempeñan la función de núcleo modal y pueden realizarse con sujeto de segunda persona y en tiempo presente, no admiten la flexión en modo imperativo, dada la naturaleza léxica de los verbos que funcionan como operadores modales y finito (Hernández, 1995). Estos grupos verbales, términos del sistema que se despliega en torno a las 'configuraciones modales obligativas', pueden ser graduados desde los que presentan un alto grado de gramaticalización y que llamamos 'perífrasis', hasta los que ostentan un mayor grado de lexicalización, esto es, 'locuciones' (Gutiérrez, 2007a, 2007b). La gradación, directamente relacionada con una disminución en el carácter obligativo de una demanda, es la que se presenta en la Figura 7.

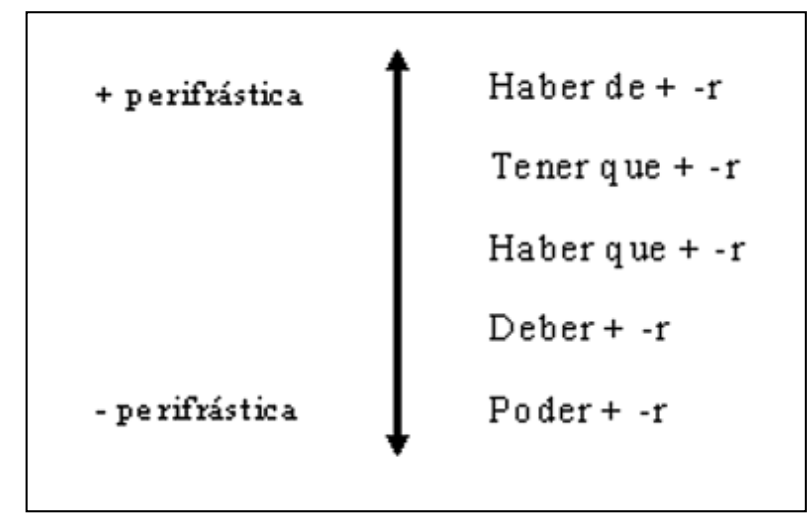

Figura 7. Gradación de los grupos verbales obligativos.

Así, por ejemplo, 'poder + -r' es una configuración en la cual los significados de modulación y modalización se combinan de tal modo que, en casi todas las instanciaciones, se hace imposible distinguirlos.

b) Grado medio de la obligación: adjetivos y adverbios obligativos

El grado medio de la obligación agrupa a configuraciones lexicogramaticales que realizan el significado obligativo fuera del marco del núcleo modal. Es 
decir, la realización lexicogramatical se ha desplazado hacia alguna de las otras funciones de la cláusula como intercambio, específicamente el desplazamiento es hacia la función de complemento, en el caso del adjetivo o hacia la de adjunto, en el caso del adverbio. Entre ellas, la que presenta mayor congruencia $y$, por tanto, mayor intensidad del significado es la realización en la función de complemento. Esto pues, de una parte, el complemento es una función que tiene la potencialidad de ser sujeto y, en consecuencia de ser parte del núcleo modal (Martin et al., 1997); y, de otra, el adjunto, en el caso de la modulación, tiende a modificar a algún elemento del residuo, es decir, no actúa sobre el significado de toda la cláusula.

Dado que nos encontramos frente a realizaciones que se distancian del núcleo modal, función que en español está altamente gramaticalizada, las configuraciones del grado medio son configuraciones que transportan léxicamente la obligación, sometiéndose a la apertura y variabilidad que caracteriza al paradigma lexical (Halliday, 2002a).

c) Grado bajo: verbos obligativos y modo interrogativo

Las configuraciones de grado bajo, por su parte, son las realizaciones que menor congruencia mantienen con el núcleo modal de la cláusula imperativa. De una parte, la conformada por 'verbo obligativo + (que)' no admite un sujeto de segunda persona ni puede ser flexionada en modo imperativo, pues la naturaleza léxica de los verbos lo impide (Hernández, 1986; Porto, 1991; Di Tullio, 1997). De otra, la configuración correspondiente a cláusulas interrogativas es la realización de menor congruencia, pues en ella se implica un cambio de modo clausular.

Como comportamiento general de las configuraciones lexicogramaticales que realizan obligación en español, podemos notar que el lugar que ocupan en la estructura funcional está directamente relacionado con el grado de obligación realizado por la construcción. Así, las que realizan el grado más alto funcionan como el núcleo modal de la estructura de la cláusula como intercambio; las que realizan el grado intermedio forman parte del residuo y entre las de grado bajo, una utiliza directamente otro modo clausular, el interrogativo, y la otra metaforiza al explicitar la obligación a través del contenido léxico del verbo cuyos morfemas flexivos realizan un núcleo modal más cercano al de las configuraciones inclinativas (Butt et al., 2000).

En síntesis, el grado de obligación implicado en una cláusula depende de tres factores: (i) de si la función desempeñada está más cercana o más lejana del núcleo de negociabilidad de la cláusula; (ii) de la congruencia y (iii) del grado de gramaticalización (o lexicalización) de la configuración. 


\section{MARCO METODOLÓGICO}

\subsection{Objetivos}

Como ya hemos señalado, el objetivo de este estudio es caracterizar el discurso especializado oral y escrito, a partir de la variación probabilística que presentan las configuraciones lexicogramaticales realizadoras del sistema de obligación en español.

Se trata de un estudio de alcance descriptivo, cuyos objetivos específicos son:

(i) Determinar la probabilidad de ocurrencia de las configuraciones de grado alto, medio y bajo de la obligación en el contexto de un corpus de registros diversificados por variable de modo (i.e. oralidad - escritura) y campo (grado de especialización).

(ii) Comparar los registros del corpus de acuerdo a la variación estadística de los perfiles probabilísticos de cada uno de los grados de obligación.

\subsection{El corpus}

En este estudio se utiliza como contexto de observación un corpus multirregistro conformado básicamente por cuatro registros correspondientes a cuatro subcorpus de El Grial (www.elgrial.cl): (i) CEO, compuesto de entrevistas orales; (ii) NOTICEN TV-2000 (NOTICEN de ahora en adelante), conformado por noticiarios de televisión; (iii) CTC, compuesto por textos escritos utilizados en la enseñanza técnico profesional y (iv) ARTICOS, compuesto de artículos de investigación científica. En tanto que registros, estas variables contextuales se definen en términos de campo y modo. Respecto del modo, los registros de este corpus se dividen en escritos, ARTICOS y CTC, y orales, NOTICEN y CEO.

Siguiendo a Halliday (1989, 2002d, 2002c, 2005a, 2005b), entendemos que oralidad y escritura son dos modos de organizar simbólicamente el significado, asociados, desde el constructo de registro, a la variable de modo (Gutiérrez, en prensa). Cada uno de estos modos puede ser caracterizado a través de los rasgos que prototípicamente presentan (Horowitz \& Samuels, 1987; Chafe \& Danielewicz, 1987; Halliday, 1989, 2002d, 2002e, 2002c, 2005a, 2005b). Sin embargo, en las instancias (i.e. en los textos o registros) los rasgos de oralidad y escritura pueden aparecer imbricados, por lo cual nos parece adecuada la idea del continuum oralidad-escritura (Horowitz \& Samuels, 1987; Chafe \& Danielewicz, 1987; Peronard, 1988), para dar cuenta de esta variable de registro.

Dispuestos en el continuum, los artículos científicos (ARTICOS) son consi- 
derados como el prototipo del texto escrito (Horowitz \& Samuels, 1987; Chafe \& Danielewicz, 1987; Peronard, 1988), le sigue CTC, luego, ubicamos a NOTICEN, el que combina rasgos de oralidad y de escritura, por cuanto, en términos generales hay una oralidad sobre la base de un texto escrito y, finalmente, el continuum se cierra con CEO, el cual, al corresponder a una interacción dialógica, directa y espontánea, es el que está más próximo al prototipo de la oralidad (Chafe \& Danielewicz, 1987; Peronard, 1988; Parodi, 2003).

Respecto del campo, esto es, de la acción social en que el lenguaje es empleado y de las condiciones de producción, circulación y consumo, ARTICOS es un corpus de artículos de investigación científica, recopilados desde el indexador ScIELO (www.scielo.com); CTC corresponde a textos utilizados como materiales de enseñanza en establecimientos técnicos profesionales de la ciudad de Valparaíso; NOTICEN contiene textos recolectados de los noticiarios centrales de cuatro canales de la televisión abierta de Chile y CEO es un corpus de entrevistas realizadas a estudiantes (www.elgrial.cl). El criterio usado para vincular los registros respecto de la variable de campo es el mayor o menor grado de especialización de los textos (Parodi, 2005). Así, los registros de nuestro corpus también pueden ser dispuestos en un continuum desde lo más especializado a lo más coloquial. De este modo, ARTICOS, al ser un corpus de artículos científicos presenta en mayor grado de especialización. Es seguido de CTC, textos en que la presentación del conocimiento específico está mediada por el propósito didáctico (Parodi, 2005), luego, por NOTICEN y, finalmente, CEO, registro que prototípicamente representa la menor especialización, tal como lo postula Parodi (2005). Además de esta disposición en continuum, utilizamos acá una nueva agrupación sobre la base de la interacción de las variables de campo y modo. De esta manera en el marco de la agrupación oralidad - escritura, distinguimos, en cada caso, un registro más especializado que el otro. En la oralidad, ese registro corresponde a NOTICEN y en la escritura a ARTICOS. La Figura 8, a continuación, sintetiza la descripción de los registros, de sus variables y su disposición en el continuum.

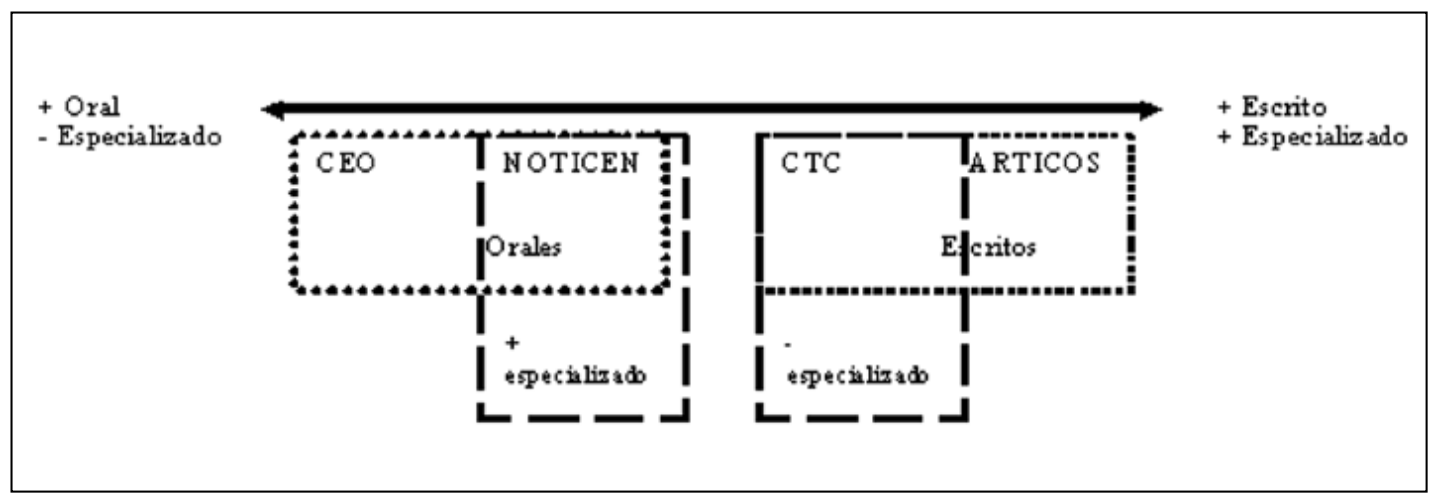

Figura 8. Descripción del corpus por variable de registro. 
Como se desprende de la Figura 8 y del comentario que la precede, los contextos de observación de esta investigación son doce: (i) cada uno de los hábeas, es decir, CEO, NOTICEN, CTC, ARTICOS; (ii) orales y escritos; (iii) especializados y no especializados; (iv) orales especializados y orales menos especializados; (v) escritos especializados y escritos menos especializados.

Cuantitativamente, el corpus está conformado por un total de 990 documentos y 3.563.082 palabras, distribuidos como se muestra en la Tabla I.

Tabla I. Caracterización cuantitativa de los registros del corpus.

\begin{tabular}{|l|l|l|}
\hline REGISTROS & $\mathrm{N}^{\text {o documentos }}$ & $\begin{array}{l}\mathrm{N}^{\mathrm{o}} \\
\text { palabras }\end{array}$ \\
\hline ARTICOS & 642 & 2.471 .389 \\
\hline CTC & 74 & 626.790 \\
\hline NoticenTV-2000 & 270 & 84.809 \\
\hline CEO & 150 & 380.094 \\
\hline Totales & 990 & 3.563 .082 \\
\hline
\end{tabular}

En términos estadísticos, el corpus multirregistro conforma una muestra probabilística estratificada y por conglomerados que busca dar cuenta de la variedad natural de la lengua.

\subsection{Variables de investigación}

A continuación se presentan las variables categórica y cuantitativa cuyo comportamiento será observado en el corpus.

a) Configuraciones lexicogramaticales que realizan modulación de obligación de la cláusula (variable categórica): las configuraciones lexicogramaticales que realizan modulación de obligación conforman, tal como lo presentáramos en el "Marco teórico", una red sistémica, donde cada término corresponde a una variable.

La Tabla II, a continuación, presenta dichas variables, distribuyéndolas por grado de intensidad. Paralelamente, da cuenta de la sintaxis empleada para desarrollar las búsquedas automáticas. 
Tabla II. Configuraciones lexicogramaticales que realizan obligación.

\begin{tabular}{|c|c|c|c|}
\hline & Configuración & \multicolumn{2}{|l|}{ Búsqued a } \\
\hline \multirow{5}{*}{$\begin{array}{l}\text { A } \\
\mathrm{L} \\
\mathrm{T} \\
\mathrm{O}\end{array}$} & Imperativo & \multicolumn{2}{|l|}{ Verbo en modo imperativo } \\
\hline & Corfiguraciones & \multicolumn{2}{|l|}{ (Hay, habría, habrá) + que+ verbo inf initivo } \\
\hline & & $\begin{array}{l}\text { (he, hemos, has, ha, han) } \\
\text { (habré, habre mos, habrás, habrá, habrán) } \\
\text { (habría, habriamos, habrías, habrian) }\end{array}$ & + de + verbo infinitivo \\
\hline & & $\begin{array}{l}\text { (tenzo, tene mos, tie nes, tie ne, tienen) } \\
\text { (tendré, tendremos, tendrás, tendrá, tendrán) } \\
\text { (tendría, tendríamos, tendrías, tendrían) }\end{array}$ & + que + verbo infinitivo \\
\hline & & $\begin{array}{l}\text { Debo, debemos, debes, debe, deben } \\
\text { Deberé, deb eremos, deberás, deberá, deberán } \\
\text { Debería, deberíamos, deberías, deberian }\end{array}$ & + verbo en infinitivo \\
\hline \multirow[t]{2}{*}{$\begin{array}{l}\text { M } \\
\text { E } \\
D \\
\text { I } \\
\text { O }\end{array}$} & Adjetivos & Es, será, sería $\quad+$ adjetivo + (que) & $\begin{array}{l}\text { Necesario } \\
\text { Obligatorio } \\
\text { Aconsejable } \\
\text { Pernitido } \\
\text { Recomend able }\end{array}$ \\
\hline & Adverbios & Adverbios de modo & $\begin{array}{l}\text { N ecesariamente } \\
\text { Obligatoriamente } \\
\text { D ebidamente } \\
\text { Indebidamente } \\
\text { A propiadamente } \\
\text { R igurosamente } \\
\text { Obligadamente } \\
\text { Fund amentalmente } \\
\text { A decuadamente } \\
\text { Forzosamente } \\
\text { Forzadamente }\end{array}$ \\
\hline \multirow[t]{2}{*}{$\begin{array}{l}\text { B } \\
\text { A } \\
\text { J } \\
O\end{array}$} & $\begin{array}{l}\text { Verbos } \\
\text { obligativos }\end{array}$ & $\begin{array}{l}\text { (se) + verbo obligativo }\left(1^{*}\right)+\text { (que, nombre o } \\
\text { grupo nominal, }-x)\end{array}$ & $\begin{array}{l}\text { Sugeriy } \\
\text { Autorizar } \\
\text { Necesitar } \\
\text { Requerir } \\
\text { Permitix } \\
\text { Aconsejar } \\
\text { Recomend ay } \\
\text { Exigir } \\
\text { Obligar } \\
\text { Pedir } \\
\text { Rogar } \\
\text { Solicitar }\end{array}$ \\
\hline & Interrogativos & $\begin{array}{l}i+(\text { me, le })+(\text { puedes, podrías })+\text { infinitivo } \\
i(\text { puedes, podrias })+\text { infinitivo }+(\text { me, le })\end{array}$ & \\
\hline
\end{tabular}


Respecto de la Tabla II, necesitamos hacer dos precisiones que tienen relación con el grado de detalle (o delicacy) al que aspira este estudio descriptivo:

(i) En primer lugar, todas las configuraciones que tienen a un verbo o a un grupo verbal como una de sus unidades formantes son buscadas en la interfaz de consulta El Grial (www.elgrial.cl), conjugando distintos sujetos y finitos. Esto, pues reconocemos, como quedó explicado en el marco teórico, que se produce una gradación de la obligación en la interacción con los sistemas de tiempo y persona (i.e. con la flexión del núcleo modal). Desde esta perspectiva, asumimos que, en general, el único finito temporomodal que queda excluido de la realización de obligación es el pasado. En efecto, como concuerdan en reconocer Rojo y Veiga (1999), Halliday y Matthiessen (2004), Palmer (2001) y Klinge y Hoeg (2005), el pasado en combinación con cualquier sujeto no realiza obligación (ni inclinación), pues no constituye propuestas, sino que proposiciones.

La gradación temporal y de persona que presenta el sistema de obligación excede el nivel de detalle que se pretende en esta descripción, razón por la cual, para cada una de las configuraciones que presentan esta gradación se han contabilizado todas las opciones presentadas en la Tabla I, pero considerándolas en su conjunto.

(ii) En segundo lugar, algunas de las configuraciones obligativas están sometidas a la variabilidad del paradigma lexical. Tal variabilidad, al igual que la de tiempo y persona, excede el grado de detalle de este trabajo, por lo cual nuestro esfuerzo se limita a realizar búsquedas homogéneas para todos los registros del corpus, siguiendo la propuesta desarrollada por Gutiérrez (2007a, 2007b) para este sistema.

En relación a este mismo tipo de configuración, es necesario señalar que el significado léxico también puede ser graduado en términos de más o menos obligativo. Sin embargo, este es un asunto propio de estudios lexicográficos o evaluativos (i.e. appraisal), motivo por el cual, las opciones son contabilizadas sin pasar al detalle de la gradación, sino que focalizándonos en un nivel más grueso, pero más cercano a los patrones lexicogramaticales.

b) Frecuencia absoluta de instanciación de las configuraciones lexicogramaticales (variable cuantitativa): medida de estadística descriptiva cuyo valor es un número que representa la cantidad de veces que una configuración es instanciada en el marco de un registro en particular. Con el propósito de determinar la frecuencia absoluta de la ocurrencia de las distintas configuraciones en el corpus, se desarrolla, como ya se dijo, una exploración automática, utilizando El Grial (www.elgrial. cl), interfaz de etiquetaje lingüístico e interrogación de corpus textual que entrega directamente los resultados de las búsquedas por frecuencia y que, además, es la que administra los registros empleados en esta investigación. 
c) Probabilidad de instanciación (variable cuantitativa): el cálculo de la probabilidad de instanciación nos permite predecir cuán posible es que las configuraciones lexicogramaticales que realizan la modulación de obligación en español sean instanciadas en registros y en variables de registro semejantes a los que son explotados en este trabajo.

Dado que trabajamos sobre la base de una representación sistémica, en la cual el término de un sistema puede ser la condición de entrada a otro sistema menor, el cálculo de la probabilidad utilizado es el de probabilidades condicionadas, éstas permiten calcular la probabilidad de ocurrencia en el marco de una condición o contexto mayor, por ejemplo, el cálculo de la probabilidad de ocurrencia del imperativo está condicionado al contexto mayor representado por el grado alto de la obligación.

El cálculo de la probabilidad se desarrolla sobre el de frecuencia y lo presentamos en términos porcentuales. Este no sólo permite caracterizar a cada configuración en el marco del contexto sistémico en que se encuentra, sino que además posibilita la caracterización de la variación del perfil probabilístico del sistema de la obligación en el marco de los diferentes registros. Para determinar si la variación entre las probabilidades de ocurrencia es estadísticamente significativa se utiliza la comparación de proporciones Z (normal estandarizada), estimándose un error global del 5\%.

\section{RESULTADOS}

Los resultados se presentan siguiendo la organización de la red sistémica de la obligación. De este modo, se consigue mostrar la caracterización del discurso especializado -oral y escrito- desde el contraste de cada configuración por grado, así como del contraste entre grados.

\subsection{Grado alto: imperativo v/s configuraciones modales}

En el marco de la probabilidad condicionada al grado alto de la obligación, el imperativo se estatuye como la forma de construir el significado obligativo que caracteriza a los registros orales de menor especialización de este corpus. Esto se evidencia no sólo porque es en dicho contexto donde presenta la mayor probabilidad de ocurrencia $(58,44 \%)$, sino que también, como podemos notar en el Gráfico 1, porque tal probabilidad tiende a disminuir a medida que la especialización de los registros y los rasgos prototípicamente asociados a la escritura aumentan, alcanzando sólo un 13, 58\% de ocurrencia en el contexto de ARTICOS (corpus de artículos de investigación científica). 


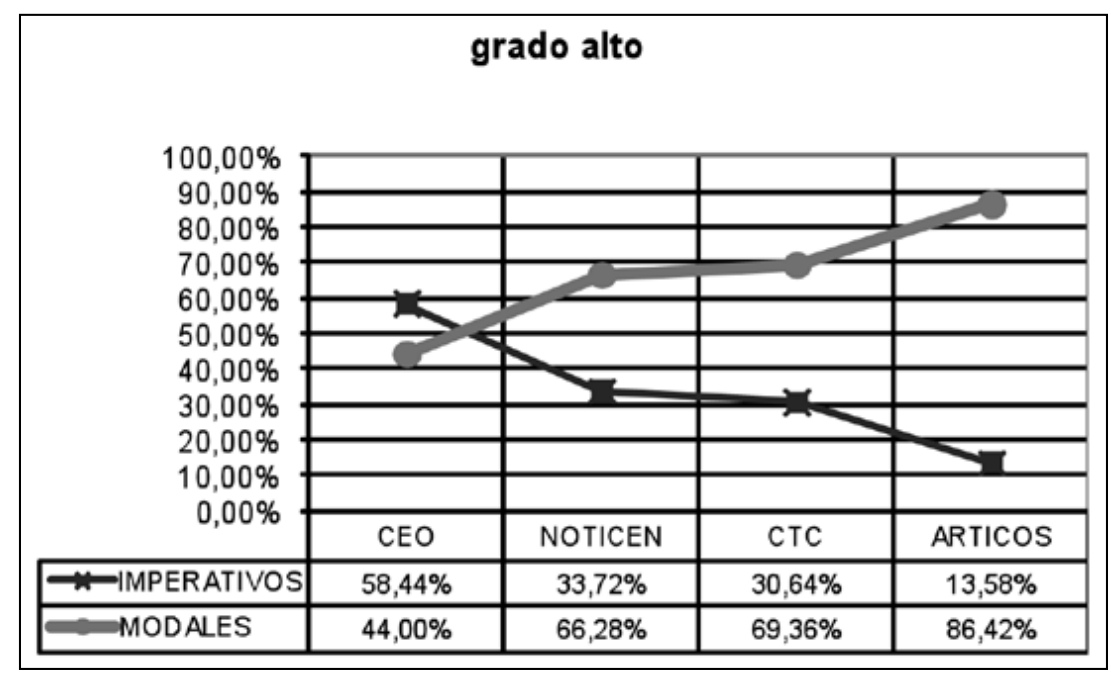

Gráfico 1. Probabilidad de ocurrencia del imperativo en los registros del corpus.

A partir de la comparación de los perfiles probabilísticos del 'imperativo' en el marco de la variable de modo, notamos que tanto en el contexto de la oralidad como en el de la escritura, la mayor probabilidad de ocurrencia corresponde a los registros de menor especialización, CEO y CTC, respectivamente. En correlación con ello, la menor probabilidad de uso se detecta en los registros de mayor especialización, NOTICEN y ARTICOS.

Si continuamos observando el Gráfico 1, notamos que las 'configuraciones modales' presentan un comportamiento semejante al del imperativo, pero inversamente éstas tienden a aumentar la probabilidad de ser usadas, a medida que el grado de especialización y los rasgos del modo escrito de uso de la lengua aumentan. De este modo, en el contexto de ARTICOS se constata la mayor frecuencia relativa, esto es $86,42 \%$, frente a un $41,66 \%$ que es la probabilidad de ocurrencia que presenta la misma configuración en CEO, registro oral de menor especialización.

En el mismo sentido de la observación anterior, la diferencia entre la probabilidad de uso de una u otra opción del grado alto de obligación es estrecha, pero estadísticamente significativa (con un error global del 5\%), en el registro más prototípicamente oral y de menor especialización (i.e. CEO). Esta diferencia se va acentuando a medida que aumenta el grado de especialización de los registros hasta alcanzar la mayor distancia en el contexto escrito más especializado (i.e. ARTICOS). El distanciamiento evidencia no sólo la preferencia de uso de la configuración menos congruente (o más metafórica) del grado alto en el marco de la especialización, sino que también demuestra que las 'configuraciones modales' constituyen formas propias -especializadas diríamos- para realizar el significado del grado alto de la obligación en el contexto de la escritura más especializada. 
En todos los casos, la variación que presentan las configuraciones obligativas de grado alto es dependiente de la variable de modo, es decir, aumentan (en el caso de las 'configuraciones modales') o disminuyen (es el caso del 'imperativo') su probabilidad de ocurrencia en estrecha relación con el aumento o disminución de los rasgos asociados a la oralidad o a la escritura, siguiendo el continuum en el que se han dispuesto los registros del corpus (ver Gráfico 1). En este sentido, el comportamiento probabilístico del 'imperativo' y de las 'configuraciones modales' refuerza planteamientos anteriores que sostienen que el mayor grado de especialización se asocia decididamente al modo escrito de uso de la lengua (e.g. Chafe \& Danielwick, 1987; Peronard, 1988; Parodi, 2005) y que los registros escritos más especializados tienden a usar con mayor frecuencia las configuraciones gramaticalmente metafóricas (metáfora ideacional) (por ejemplo, Cademártori et al., 2007; Marinkovich, 2007; Gutiérrez 2009b).

\subsection{Grado medio: adjetivos v/s adverbios obligativos}

Al igual que ocurría en el marco del grado alto, las probabilidades de ocurrencia que presentan las dos configuraciones lexicogramaticales que realizan el grado medio de la obligación conforman perfiles de tendencias inversas entre sí. Esto quiere decir que una de ellas, 'ser + adjetivo obligativo + (que)', es característica de la oralidad menos especializada, en tanto que la otra, los 'adverbios', lo es de la escritura más especializada, tal como se expone a través del Gráfico 2. La misma gráfica deja en evidencia que, aun cuando se mantienen los perfiles inversos, los registros más especializados, independiente de la variable de modo, presentan una mayor proximidad entre las probabilidades de ocurrencia de una y otra configuración. En tanto que ésta se distancia en el marco de la menor especialización.

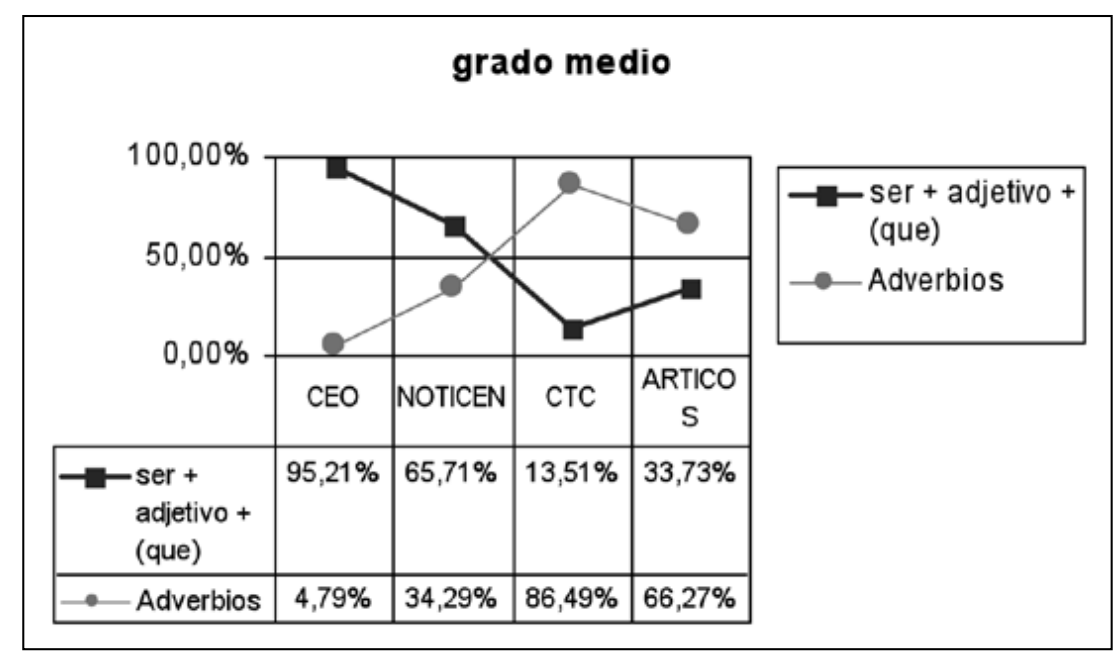

Gráfico 2. Probabilidad de ocurrencia de las configuraciones de grado medio. 
En la distancia que separa las ocurrencias de una y otra configuración, podemos reconocer una tendencia relacionada con la variable de modo, pues CEO presenta el mayor distanciamiento, en tanto que ARTICOS, el menor. Este asunto tendría estrecha relación con las modalidades de organización textual asociadas a nuestros registros de trabajo. Así, el predominio de adverbios, definidos como adjuntos que refuerzan la demanda, en ARTICOS y CTC se vincula con el carácter argumentativo de los artículos de investigación científica y con el énfasis didáctico de la presentación del conocimiento en los textos de la enseñanza técnico-profesional. En otras palabras, se relaciona con una presentación del conocimiento que requiere ser más 'creíble'. Inversamente, en la oralidad, el predominio de la configuración de adjetivo presenta la obligación como un estado de cosas, lo que se relaciona con el carácter narrativo de las entrevistas orales de $\mathrm{CEO}$ y de las noticias de televisión en NOTICEN.

Resulta interesante mencionar que, en relación a los 'adverbios' que realizan léxicamente la obligación, desde otros estudios como el de Biber (2006), para el inglés, y los de Gutiérrez (2009a, b), para el español, también se constata que los 'adverbios' ocurren con mayor frecuencia en los registros escritos y didácticos, constituyéndose, por tanto, en un rasgo lingüístico prototípicamente asociado a la escritura didáctica especializada. Esto se condice con el hecho de que esta configuración presente la ocurrencia más alta en el contexto proporcionado por CTC, registro constituido por textos empleados en la enseñanza técnico-profesional.

Del mismo modo que en el grado alto, en el grado medio es posible reconocer que la congruencia es un fenómeno que varia en directa relación con las variaciones de modo y campo que describen a los registros del corpus. Así, la configuración de mayor congruencia, esto es la que realiza la obligación en el complemento de la estructura funcional de la cláusula como intercambio, presenta su mayor probabilidad de ocurrencia en CEO, el registro oral de menor especialización. En tanto que la menos congruente (adverbios) es más usada en los registros escritos de mayor especialización. De este modo, en el contexto del grado medio vuelve a comprobarse que la escritura y la mayor especialización se asocian a la mayor frecuencia de uso de las configuraciones metafóricas.

\subsection{Grado bajo: verbos obligativos v/s modo interrogativo}

El Gráfico 3 presenta el contraste entre los perfiles probabilísticos de las dos configuraciones lexicogramaticales que realizan la obligación en su grado más bajo o metafórico. Dicho contraste es bastante más marcado que el que se produce al interior de los grados alto y medio. En efecto, en tres de los registros, el oral más especializado y los dos escritos, la diferencia entre las ocurrencias alcanza o está cercana a un $100 \%$ frente a un $0 \%$ (ver Gráfico 4). Esto sella un comportamiento probabilístico inverso, en el marco de contextos de observación semejantes respec- 
to del grado de especialización, sea ésta en relación al corpus total o al interior de la variable de modo.

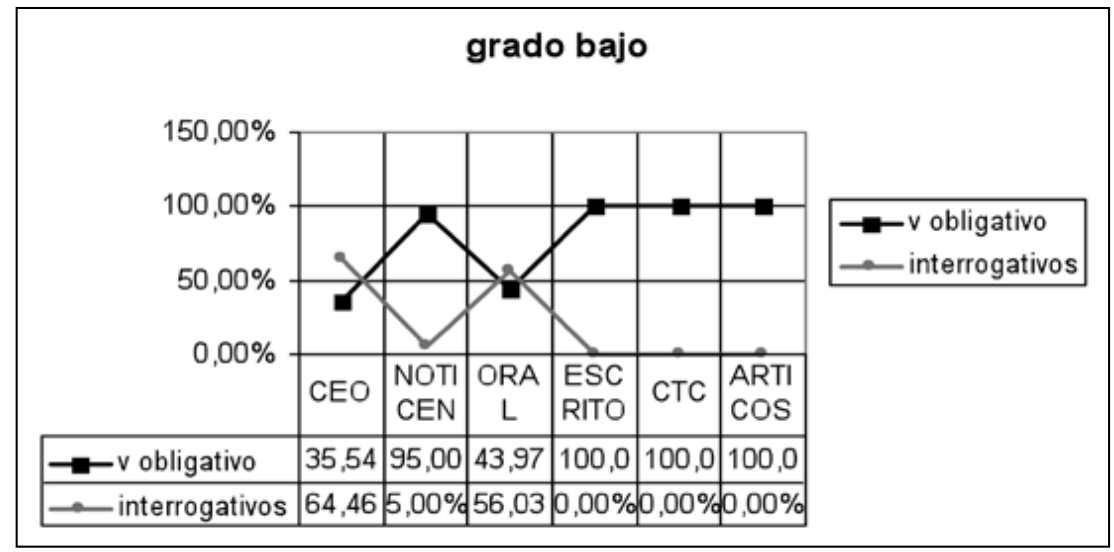

Gráfico 3. Probabilidad de ocurrencia de las configuraciones de grado bajo en los registros.

Como muestra el Gráfico 3, la configuración lexicogramatical que alcanza el $100 \%$ de ocurrencia en los registros escritos de mayor especializados es más congruente (o menos metafórica) que su par, 'configuraciones interrogativas'. A consecuencia de ello, el grado bajo es el único de los tres grados en el cual la mayor especialización no está asociada a la menor congruencia. Creemos que esto se debe a que estamos frente a las dos configuraciones lexicogramaticales que son reconocidas como metáforas de modo en su propio derecho (Martin et al., 1997; Halliday \& Matthiessen, 2004) y, por tanto, parece lógico sustentar la idea de que cada uno de los modos de uso de la lengua (i.e. oral o escrito) utilice su propio y específico mecanismo lexicogramatical para metaforizar la realización de la obligación. En atención a lo anterior, resulta interesante notar la paradoja que se configura en el registro oral menos especializado (CEO), pues en este contexto se presenta la mayor probabilidad de ocurrencia de la configuración más congruente, más gramaticalizada y más directamente obligativa, a la vez que también la mayor probabilidad de ocurrencia de la configuración más metafórica y más indirectamente obligativa (i.e. interrogaciones). Frente a las diferencias que se han descrito para una y otra configuración, surge, entonces, un punto de comunión: ambas son más usadas en la oralidad de menor especialización y esto puede deberse a que las dos tienden a la condensación de los significados, haciéndose, en el caso del imperativo, implícitos (o implícitamente apelativos) y en el de la interrogación, indirectos.

\subsection{Síntesis}

Hasta aquí hemos estado observando la variación intra e interregistros y desde 
ella, tal como lo muestra el Gráfico 4, estamos en posición de constatar que las configuraciones de grado alto, esto es, las más congruentes y más gramaticalizadas presentan, en todos los casos, la mayor probabilidad de ocurrencia. Esto quiere decir que, sin importar las variables que caracterizan a los registros, en ellos se prefiere construir la obligación de modo directo, a través de las configuraciones más gramaticalizadas y de mayor congruencia, es decir, de aquellas que presentan la obligación directamente, en el núcleo modal, como centro de la negociabilidad de la cláusula. Sobre esta base, observamos, con un grado de detalle más avanzado, que la mayor probabilidad de ocurrencia de las configuraciones de grado alto se presenta en el registro oral de menor especialización (CEO) y que dicha probabilidad tiende a disminuir a medida que los rasgos prototípicos de la escritura y el grado de especialización aumentan. La situación inversa se presenta en el grado medio, cuyas configuraciones ocurren con mayor probabilidad en los registros escritos más especializados, tendiendo a disminuir a medida que se avanza hacia la oralidad menos especializada.

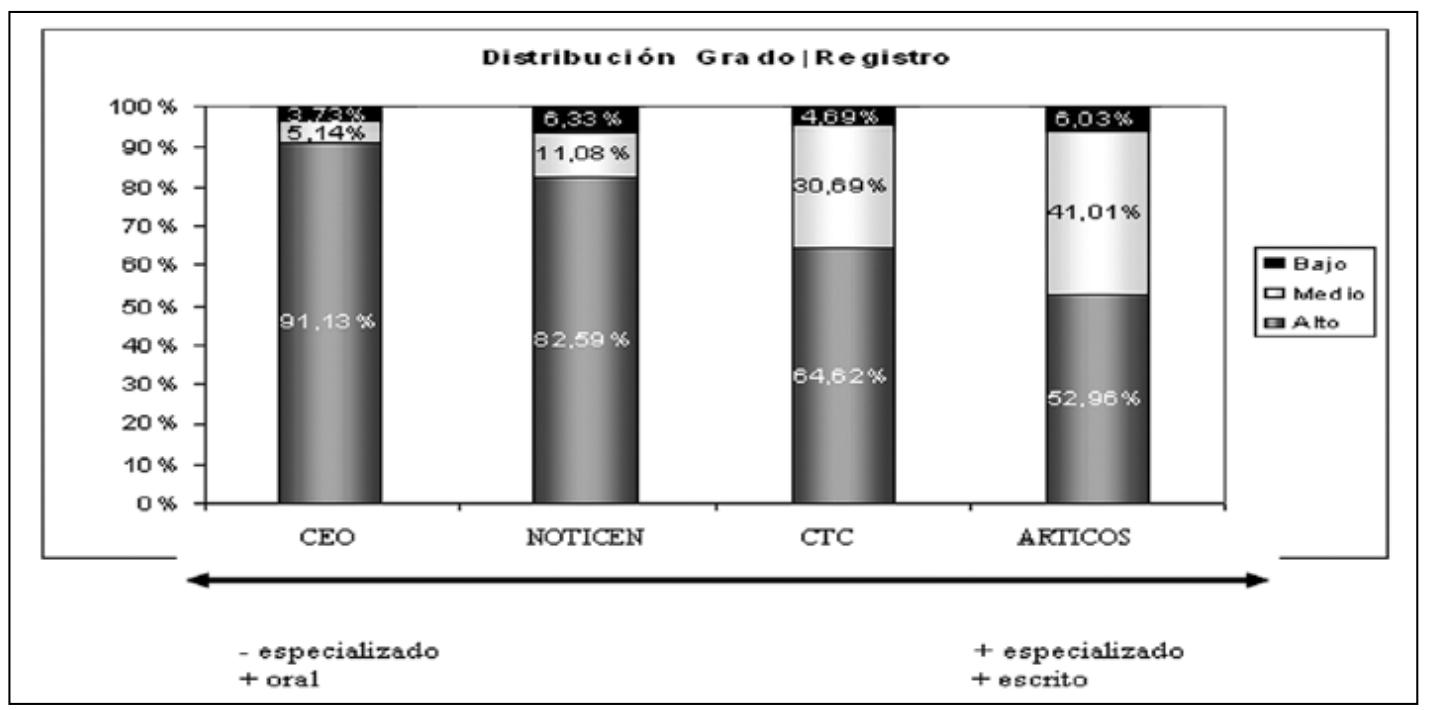

Gráfico 4. Distribución de la probabilidad de ocurrencia de cada grado en los registros del corpus.

En consecuencia, un registro escrito y especializado estaría más modulado que uno oral de baja especialización. En otras palabras, en un registro más especializado se emplean más mecanismos tendientes a atenuar la demanda directa, tal como se evidencia en el hecho de que las configuraciones obligativas de grado medio, según el Gráfico 4, aumentan su probabilidad de ocurrencia en los registros escritos de mayor especialización. Esta preferencia por la atenuación o metaforización de la demanda puede ser entendida como un mecanismo de cortesía, al relacionarse con el vínculo formal que se establece entre los participantes del evento de habla en el marco de la mayor especialización; o como una estrategia funcional, al estar 
relacionado con los mecanismos más explícitos que se requiere usar cuando tales participantes no están co-presentes y la intención comunicativa no puede inferirse desde factores tales como la entonación (o modulación, según terminología del funcionalismo ruso). Pero, fundamentalmente, más modulado quiere decir más abierto a la negociación del conocimiento (en el caso de los registros del corpus), más fluctuante y menos estático. Situación que está en consonancia con la descripción de las configuraciones que realiza esta negociación a nivel lexicogramatical: apertura y variabilidad del paradigma léxico, tendencia a la atenuación de la demanda, menor congruencia.

El grado bajo, por su parte, es el que menor ocurrencia presenta en el corpus total y, desde la perspectiva interregistros, constituye una forma de construir obligación que es más utilizada en NOTICEN y en ARTICOS, registros que hemos caracterizado como el oral más especializado y el escrito más especializado, respectivamente.

Finalmente, resulta interesante notar que la regularidad con el sistema de la obligación varía en el marco de los registros del corpus, así como también el constatar que tal variación se produce en el sentido de los continuum de oralidad - escritura y grado de especialización que hemos utilizado para disponer el corpus.

\section{CONCLUSIONES}

Como observamos a partir de la exposición de los resultados. la variación del sistema de la obligación, en el marco del corpus utilizado, se relaciona directamente con el grado de especialización de los textos o registros, permitiendo, en consecuencia, identificar configuraciones lexicogramaticales que tienden a comportarse como rasgos críticos en la caracterización del grado de especialización de los textos. En este sentido, habría configuraciones que caracterizan a los registros orales y escritos de mayor o menor especialización. Así, las 'configuraciones modales', los 'adverbios' y '(se) verbo obligativo (1a) + (que)', una de cada grado de la obligación, son características de los registros escritos y más especializados. Cada una de estas configuraciones es además, dentro de su respectivo grado, la de menor congruencia o más metafórica. Dado que este último es un fenómeno que, como hemos visto, se repite tanto a nivel interpersonal como a nivel ideacional y que se replica en el cruce de las variables de modo y campo, sostenemos que la metáfora es un recurso propio y, en consecuencia, característico de la escritura y de la mayor especialización. En efecto, la metáfora gramatical es un medio depurado y abstracto, que surge, esencialmente, por la necesidad de especializar el significado a medida que el conocimiento se especializa. En este sentido es que podemos sostener que la metáfora es un fenómeno que está estrechamente vinculado a la ontegénesis de la lengua y, en consecuencia, al tiempo (Gutiérrez, 2009b). 
La metáfora interpersonal, como se ha dicho, está directamente vinculada a la mayor lexicalización. Esto nos lleva a sostener que los registros escritos y especializados del corpus se caracterizan por construir la obligación a través de recursos léxicos, lo que está en directa relación con caracterizaciones anteriores que se han desarrollado sobre estos mismos registros o sobre las variables que los definen (e.g. Chafe \& Danielewicz, 1987; Peronard, 1988; Halliday, 2005a, 2005b; Parodi, 2005). En efecto, y ésta es una de las razones para sostener que la escritura es más compleja que la oralidad, los registros escritos se caracterizan, en general, por presentar mayor variabilidad léxica que los orales. En el marco de la oralidad, dicha variabilidad léxica se ve compensada por una mayor diversidad de configuraciones para expresar obligatoriedad, como se constata al observar que las configuraciones en los grados alto y bajo tienden a presentar ocurrencias más cercanas. Precisamente, es el uso de una mayor heterogeneidad de estructuras lexicogramaticales el factor que ha llevado a Halliday $(1989,2002 d$, e) a sostener que la oralidad es mucho más compleja que la escritura.

Dado que se comprueba que su variación permite diferenciar sobre una base estadística significativa, la obligación es un sistema que puede aportar a la caracterización de la oralidad, de la escritura y de la especialización.

Las principales conclusiones pueden resumirse en los siguientes puntos:

(i) A menor especialización, mayor uso de configuraciones realizadoras del grado alto de la obligación o menos metafóricas.

(ii) A menor especialización, menor uso de configuraciones realizadoras del grado medio de la obligación.

(iii) A menor especialización, menor uso de configuraciones realizadoras del grado bajo de la obligación o menos congruentes.

(iv) A mayor especialización, mayor uso de configuraciones realizadoras de grado bajo o menos congruentes.

Este conjunto de conclusiones permite también visualizar algunas de las proyecciones de este estudio, por ejemplo, su ampliación, a través del estudio de la variación del sistema de la obligación en otros registros o la constatación de las correlaciones en un corpus mayor.

\section{REFERENCIAS}

Alarcos, E. 1999. Gramática de la lengua española. Madrid: Espasa Calpe. Benveniste, E. 1969. Problemas de lingüistica general. Buenos Aires: Sudamericana.

Biber, D. 2006. University language: a corpus based study of spoken and written register. Amsterdam: Benjamins. 
Bosque, I. \& Demonte, V. 1999. Gramática descriptiva de la lengua española. Madrid: Espasa Calpe.

Bosque, I. 1990. Tiempo y aspecto en español. Madrid: Cátedra.

Butt, D., Fahey, R., Feez, S., Spinks, S. \& Yallop, C. 2000. Using functional grammar. An explorer's guide. Sydney: Macquarie University.

Cademártori, G., Parodi, G. \& Venegas, R. 2007. El discurso escrito y especializado: Las nominalizaciones en los manuales técnicos. En G. Parodi (Ed.), Lingüística de corpus y discursos especializados: Puntos de Mira, pp 79-98. Valparaíso: Ediciones Universitarias de Valparaíso.

Caffarel, A., Martin, J. \& Matthiessen, Ch. 2004. Language typology. A functional perspective. Amsterdam: Benjamins.

Chafe, W. \& Danielewicz, J. 1987. Properties of spoken and written language. En R. Horowitz \& S. Samuels (Eds.), Comprehending oral and written language, pp. 83-113. New York: Academic Press.

Di Tulio, A. 1997. Manual de gramática del español. Desarrollos teóricos. Ejercicios, soluciones. Buenos Aires: Edicial.

Escandell, M. 1999. Los enunciados interrogativos. Aspectos semánticos y pragmáticos. En I. Bosque \& V. Demonte (Dir.), Gramática descriptiva de la lengua española, pp. 3929-3991. Vol. 3. Madrid: Espasa Calpe.

Garrido, J. 1999. Los actos de habla. Las oraciones imperativas. En I. Bosque \& V. Demonte (Dir.), Gramática descriptiva de la lengua española, pp. 3879-3928. Vol. 3. Madrid: Espasa Calpe.

Gili Gaya, S. 1979. Curso superior de sintaxis española. Barcelona: Biblograf.

Gómez, L. 1988. Perífrasis verbales. Madrid: Arcos.

Gómez- Macker, L. 2005. Tú y yo. Una aproximación integral al proceso dialógico. En M. Peronard \& X. Gómez (Eds.), El hombre y su palabra, pp. 147-165. Valparaíso: Ediciones Universitarias de Valparaíso.

Gotti, M. 2003. Specialized discourse: Linguistic features and changing conventions. Berna: Peter Lang.

Gutiérrez, RM. 2007a. Realización lexicogramatical del sistema semántico de la modulación: Una aproximación a la descripción sistémico-funcional del español. Tesis del Doctorado en Lingüística, Pontificia Universidad Católica de Valparaíso, Chile.

Gutiérrez, RM. 2007b.Oralidad, escritura y especialización: Una caracterización desde el sistema de la modulación. En G. Parodi (Ed.), Lingüística de corpus y discursos especializados: Puntos de Mira, pp. 149-178. Valparaíso: Ediciones Universitarias de Valparaíso.

Gutiérrez, RM. 2009a. La regulación del conocimiento en el género Manual: caracterización desde el sistema de la obligación. En G. Parodi (Ed.), Géneros académicos y géneros profesionales: Accesos discursivos para saber y hacer, pp. 247268. Valparaíso: Ediciones Universitarias de Valparaíso. 
Gutiérrez, RM. 2009b. Metáfora gramatical en la representación y negociación del conocimiento. En G. Parodi (Ed.), Géneros académicos y géneros profesionales: Accesos discursivos para saber y hacer, pp. 269-288. Valparaíso: Ediciones Universitarias de Valparaíso.

Halliday, M. 1982a. Exploraciones sobre las funciones del lenguaje. Barcelona: Editorial médica y técnica $S$. A.

Halliday, M. 1982b. El Lenguaje como Semiótica Social. La Interpretación Social del Lenguaje y del Significado. México: Fondo de Cultura Económica.

Halliday, M. 1984. Language as code and language as behaviour: a systemicfunctional interpretation of the nature and ontogenesis of dialogue. En R. Fawcett, M. Halliday, S. Lamb \& A. Makkai (Eds.). The semiotics of culture and languague. Vol 1, pp. 2-35. London: Frances Pinter.

Halliday, M. 1985a. An Introduction to Functional Grammar. London: Arnold. Halliday, M. 1985b. Systemic background. En J. Benson \& W. Greaves (Eds.), Systemic Perspective on discourse. Vol 1, pp. 1-15. Estados Unidos: Ablex.

Halliday, M. 1989. Spoken and written language. Hong Kong: Oxford University Press.

Halliday, M. 2002a. On Grammar and Grammatics (1996). En J. Webster (Ed.), On grammar, pp. 384-417. London: Continuum.

Halliday, M. 2002b. Class in Relation to the Axes of Chain and Choice in Language (1963). En J. Webster (Ed.), On grammar, pp. 95-105. London: Continuum.

Halliday, M. 2002c. Lexis as a Linguistic Level (1966). En J. Webster (Ed.), On grammar, pp. 158-172. London: Continuum.

Halliday, M. 2002d. How Do You Mean? (1992). En J. Webster (Ed.), On grammar, pp. 352-368. London: Continuum.

Halliday, M. 2002e. Modes of Meaning and Modes of Expression: Types of Grammatical Structure and Their Determination by Different Semantic Functions (1979). En J. Webster (Ed.), On grammar, pp. 196-218. London: Continuum.

Halliday, M. 2005a. Linguistics and machine translation (1962). En J. Webster (Ed.), Computational and quantitative studies, pp. 20-35. London: Continuum.

Halliday, M. 2005b. Corpus studies and probabilistic grammar (1991). En J. Webster (Ed.), Computational and quantitative studies, pp. 63-75. London: Continuum.

Halliday, M. \& Matthiessen, C. 2004. An Introduction to Functional Grammar. London: Arnold.

Hernández, C. 1986. Gramática funcional del español. Madrid: Gredos.

Hernández, C. 1995. Nueva sintaxis de la lengua española. Salamanca: Ediciones Colegio de España. 
Horowitz, R. \& Samuels, S. 1987. Comprehending Oral and Written Language: Critical Contrasts for literacy and Schooling. En R. Horowitz \& S. Samuels (Eds.), Comprehending Oral and Written Language, pp. 1-52. New York: Academic Press INC.

Ibáñez, R. 2009. El Texto Disciplinar y el acceso al conocimiento desde el análisis del género: ¿Regulación del conocimiento o persuasión? En G. Parodi (Ed.), Géneros académicos y géneros profesionales: Accesos discursivos para saber y hacer, pp. 219-248. Valparaíso: Ediciones Universitarias de Valparaíso.

Klinge, A. \& Hoeg, H. 2005. Modality. Studies in form and function. London: Equinox.

Marinkovich, J. (2007). La nominalización como recurso de cohesión léxica en los manuales de la formación técnico-profesional. En G. Parodi (Ed.), Lingüística de corpus y discursos especializados: Puntos de Mira, pp. 97-114. Valparaíso: Ediciones Universitarias de Valparaíso.

Martin, J. 1992. English Text. System and Structure. Philadelphia: Benjamins.

Martin, J., Matthiessen, C. \& Painter, C. 1997. Working with functional grammar. London: Arnold.

Matthiessen, C. 1995. Lexicogrammatical Cartography: English System. Tokyo: Meadea. Matthiessen, C. 2006. Frequency profiles of some basic grammatical systems: an interim report. En G. Thompson \& S. Hunston (Eds.), System and Corpus. Exploring Connections, pp. 103-142. London: Equinox.

Matthiessen, C. 2007. "The architecture" of language according to the systemic functional theory of language. En Book, 10, pp. 505-561.

Palmer, F. 2001. Mood and modality. Cambridge: Cambridge University Press.

Parodi, G. 2003. Relaciones entre lectura y escritura: Una perspectiva cognitiva discursiva. Valparaíso: Ediciones Universitarias de Valparaíso.

Parodi, G. 2005. Discurso especializado e instituciones formadoras. En G. Parodi (Ed.), Discurso especializado e instituciones formadoras, pp. 83-126. Valparaíso: Ediciones Universitarias de Valparaíso.

Parodi, G. 2007. El Grial: Interfaz computacional para anotación e interrogación de corpus en español. En G. Parodi (Ed.), Lingüística de corpus y discursos especializados: Puntos de Mira, pp. 79-98. Valparaíso: Ediciones Universitarias de Valaparaíso.

Parodi, G. 2009. El género Manual y su organización retórica en cuatro disciplinas científicas: Entre la abstracción y la concreción. En G. Parodi (Ed.), Géneros académicos y géneros profesionales: Accesos discursivos para saber y hacer, pp. 199-218. Valparaíso: Ediciones Universitarias de Valaparaíso.

Parodi, G., Venegas, R., Ibáñez, R., Gutiérrez, RM. 2009. Géneros del discurso en el Hábeas PUCV-2006: Criterios, definiciones y ejemplos. En G. Parodi (Ed.), Géneros académicos y géneros profesionales: Accesos discursivos para saber y hacer, pp. 39-74. Valparaíso: Ediciones Universitarias de Valparaíso. 
Peronard, M. 1988. El Hombre que Habla; El Hombre que Escribe. Boletín Academia Chilena de la Lengua, 68, pp. 59-77.

Porto, J. 1991. Del indicativo al subjuntivo: Valores y usos de los modos del verbo. Madrid: Arco Libros.

RAE. 1973. Esbozo de una nueva gramática de la lengua española. Madrid: Espasa Calpe.

Rojo, G. \& Veiga, A. 1999. El tiempo verbal. Los tiempos simples. En I. Bosque \& V. Demonte (Dir.), Gramática descriptiva de la lengua española, pp. 28672934. Vol. 2. Madrid: Espasa Calpe.

Sabaj, O. 2007a. Los esquemas preposicionales en verbos de comunicación. En G. Parodi (Ed.), Lingüística de corpus y discursos especializados: Puntos de Mira, pp. 179-206. Valparaíso: Ediciones Universitarias de Valparaíso.

Sabaj, O. 2007b. El uso de los participantes semánticos en los predicados de cambio de estado. En G. Parodi (Ed.), Lingüística de corpus y discursos especializados: Puntos de Mira, pp. 115-148. Valparaíso: Ediciones Universitarias de Valparaíso.

Seco, R. 1980. Manual de gramática española. Madrid: Aguilar.

Tognini-Bonelli, E. 2001. Corpus linguistics at work. Amsterdam: Benjamins. 